\title{
Improving the Security and Efficiency of Self Bag Drop Systems: Proposals Based on the Current State of the Technology and Aviation Accident Cases
}

\section{Kang-Seok Lee ${ }^{1}$ and Ha-Na Kim ${ }^{2 *}$}

${ }^{1}$ Department of Air Transportation and Logistics, Aeronautical Science Division, Hanseo University, South Korea

${ }^{2}$ Department of Flight Operation and Management, Hanseo University, South Korea

\begin{abstract}
The self-bag drop (SBD) system enables passengers to complete all boarding procedures, from issuing air tickets to consigning baggage, by themselves. The SBD system has various advantages, such as improving the speed of passenger circulation, decreasing waiting time during check-in, and reducing airlines' operational costs. However, this system faces the potential threat of use as a tool for air terrorism, given that it is a new technology. This study intended to determine methods to improve the security and efficiency of the SBD system by investigating the existing literature on SBDs, self-check-in, airport security, air terrorism, aviation accidents, risk management, and information security. To gather real-time information about SBD operations, this study examined 12 airports in North America, Europe, and Asia based on previous studies of international SBD trends. The results reveal that the root causes of accidents and other problems are the absence of regulations and policies, human errors, and irregular information sharing among organizations. Thus, a process for justifying the necessity of new security measures through valid risk assessment is required.
\end{abstract}

Keywords: Self Bag Drop (SBD) System; Airport security; Aviation accidents; Airport operations; Risk management

\section{Introduction}

In the past, aviation demand was low because air travel was hard to access. Today however, international airports are saturated by the ever-increasing number of air passengers. Airbus-2015 [1], an aircraft manufacturer, predicted aviation demand using Revenue Passenger Kilometers (RPK), as illustrated in Figure 1. RPK is the number of revenue passengers multiplied by the flight distance. Thus, it is not only a significant measure of judging airlines' scale but is also a good indicator of increases in aviation demand.

In order to accommodate this forecasted demand, many international airports are currently in their expansion or planning stages. However, airports are congested repeatedly after a certain amount of time due to the fast-rising demand for air transport. Thus, airport expansion has some limitations, such as providing only shortterm relief from congestion and the limited ability to improve airport capacity compared to the invested time and capital [2,3] Accordingly, some studies investigate improvements to airports' fundamental

RPK traffic by airline domicile (billions)

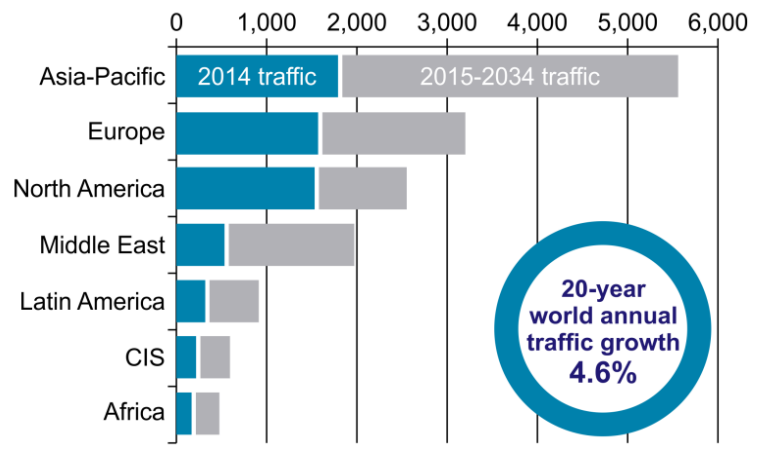

Figure 1: Predicted increase in aviation demand for 2015-2034 [1]. operating procedures to increase their passenger accommodation capacity $[2,4]$.

As a part of their efforts to improve passenger circulation speed, airports utilize various self-check-in methods such as mobile/internet check-in. This has positive effects on airport congestion by reducing the time consumed by check-in procedures [5-11]. Nevertheless, the use rate of such methods is low since passengers have to eventually visit the airline's check-in counter to consign their baggage [3]. Thus, luggage is a significant obstacle to achieving a complete self-check-in [9].

The self-bag drop (SBD) method was developed to solve this problem [12]. Using this method, passengers can complete all boarding procedures from issuing air tickets to consigning baggage by themselves. SBD has improved airport capacity by accelerating the speed of passenger circulation [13]. Kim and Yoon [14] demonstrated the feasibility of IATA's Fast Travel Program, which aims to streamline passenger processing. With the current trend, achieving IATA's goal appears achievable, though there are some challenges to address, such as the need for new regulations, equipment, and application scope [15]

Due to factors such as congested airports being a potential security threat, customer dissatisfaction, and potential revenue losses for airports and airlines due to overcrowding [3], SBD has a very positive effect on airport operations and airport security because it can reduce the level of

*Corresponding author: Ha-Na Kim, Department of Flight Operation and Management, Hanseo University, South Korea, Tel: +82-10-8385-4355; E-mail: kimhana6337@naver.com

Received January 19, 2018; Accepted February 02, 2018; Published February 09, 2018

Citation: Lee K, Kim H (2018) Improving the Security and Efficiency of Self Bag Drop Systems: Proposals Based on the Current State of the Technology and Aviation Accident Cases. J Astrophys Aerospace Technol 6: 158. doi:10.4172/23296542.1000158

Copyright: (c) 2018 Lee $\mathrm{K}$, et al. This is an open-access article distributed under the terms of the Creative Commons Attribution License, which permits unrestricted use, distribution, and reproduction in any medium, provided the original author and source are credited. 
Citation: Lee K, Kim H (2018) Improving the Security and Efficiency of Self Bag Drop Systems: Proposals Based on the Current State of the Technology and Aviation Accident Cases. J Astrophys Aerospace Technol 6: 158. doi:10.4172/2329-6542.1000158

Page 2 of 6

airport congestion. However, since passengers independently handle all boarding procedures, there is a possibility that SBD can be used as a tool for air terrorism. Thus, although efforts to find relevant literature on SBD security are underway, they are difficult to identify from an aeronautical perspective. Alternatively, there are few studies on SBD's overseas trends and system analyses. Accordingly, this study explores ways to improve SBD security and efficiency by analyzing the existing literature related to airport security and aviation accidents.

\section{Research Method and Background}

\section{Research method}

This research analyzed the existing international literature on SBD, self-check-in, airport security, airline terrorism, aviation accidents, risk management, and information security. To investigate aviation accidents, data was collected from related publications [16-18] and the Aeronautical Information Portal System website maintained by the Korean Ministry of Land and Transport [19]. Integrating the prior literature yielded several suggestions for the potential future direction of SBD. The results from this combined analysis were used to suggest measures to improve the security and efficiency of SBD.

\section{SBD operations}

SBDs can be operated by two methods: 1-step and 2-step. In the 1-step method, issuing both air tickets and bag tags in addition to baggage consignment is processed by SBD equipment. Since all boarding procedures are handled by one device, it increases airport spatial effectiveness. However, one drawback is that passengers not carrying any luggage also have to undergo the same procedures, which is more time-consuming for them.

The 2-step method uses two different types of equipment: the self-check-in kiosk to print boarding passes, and the SBD to issue bag tags and check-in luggage. Separating the printing of air tickets and baggage check-in can alleviate congestion in the SBD zone and reduce processing time by dispersing air passengers to two places. However, since the two devices are located in different locations, it can decrease airport space efficiency because passengers need to move to the SBD zone to consign their baggage [3].

To gather real-time information about SBD operations, this study examined 12 airports in North America, Europe, and Asia based on previous studies into international SBD trends conducted by Lee and Ji [2] and Lee and Lee (2015). The North American airports studied include the Los Angeles International Airport (LAX), Dallas Fort Worth International Airport (DFW), Chicago O'Hare International Airport (ORD), Philadelphia International Airport (PHL), and Toronto International Airport (YYZ) [20]. The European airports include the Orly International Airport (ORY), Frankfurt Airport (FRA), Schiphol International Airport (AMS), Brussels Airport (BRU), and London Heathrow Airport (LHR) [2]. The Asian airports include the Hong Kong International Airport (HKG) [2] and Incheon International Airport (ICN). The detailed illustrations of the SBDs' security and operational items are described in Table 1.

\section{Aviation accident data}

While differences exist among countries in defining aviation accidents, the definition of Annex 13 is the international standard [21]. The aviation accident analysis covers the period from 1931 to 2014. The starting point is when the first air terror activity occurred. Since the data was collected at the end of 2015 , the last point of the data is 2014. In this study, causes of aviation accidents are classified into four

\begin{tabular}{|c|c|}
\hline Variables & $\begin{array}{l}\text { Details (Number of airports/Total number of airports: IATA } \\
\text { identification code) }\end{array}$ \\
\hline \multirow{5}{*}{ Security items } & $\begin{array}{l}\star \text { Security personnel deployed in the SBD Zone. (6/12: ORY, } \\
\text { FRA, AMS, BRU, LHR, HKG) }\end{array}$ \\
\hline & $\begin{array}{l}\star \text { Identity verification by device or security personnel prior to } \\
\text { entering the SBD Zone. (5/12: LAX, DFW, ORD, ORY, LHR) }\end{array}$ \\
\hline & $\begin{array}{l}\star \text { Conveyor belts operated to move the baggage checked in by } \\
\text { the SBD to the security zone. (4/12: DFW, ORD, PHL, YYZ) }\end{array}$ \\
\hline & $\begin{array}{l}\star \text { Personnel assigned to move the baggage checked in by the } \\
\text { SBD to the security zone. }(1 / 12: \text { LAX) }\end{array}$ \\
\hline & $\begin{array}{l}\star 5 \text { minute-waiting time required to inspect after consignment. } \\
(1 / 12: \text { ICN) }\end{array}$ \\
\hline \multirow{13}{*}{ Operational } & $\begin{array}{l}\star \text { SBDs operated using the 2-step way. (12/12: LAX, DFW, ORD, } \\
\text { PHL, YYZ, ORY, FRA, AMS, BRU, LHR, HKG, ICN) }\end{array}$ \\
\hline & $\begin{array}{l}\star \text { Airline staff placed for security assistance in the SBD Zone. } \\
\text { (10/12: LAX, DFW, ORD, ORY, FRA, AMS, BRU, LHR, HKG, ICN) }\end{array}$ \\
\hline & $\begin{array}{l}\star \text { When abnormalities such as overweight occur, the passengers } \\
\text { and baggage are led to manned check-in counters. (7/12: ORY, } \\
\text { FRA, AMS, BRU, LHR, HKG, ICN) }\end{array}$ \\
\hline & $\begin{array}{l}\star \text { Different self-kiosk systems used by each airline. (6/12: LAX, } \\
\text { DFW, YYZ, BRU, LHR, BRU) }\end{array}$ \\
\hline & $\begin{array}{l}\star \text { SBDs used only for domestic flights. (5/12: LAX, DFW, ORD, } \\
\text { PHL, ORY) }\end{array}$ \\
\hline & $\begin{array}{l}\star \text { SBDs used only by specific airline alliance groups. (4/12: FRA, } \\
\text { AMS, BRU, LHR) }\end{array}$ \\
\hline & $\star$ SBDs used only by certain airlines. (3/12: ORY, HKG, ICN) \\
\hline & $\begin{array}{l}\star \text { Additional staff placed during peak hours. (5/12: LAX, DFW, } \\
\text { ORD, PHL, YYZ) }\end{array}$ \\
\hline & $\star$ SBDs used only for international flights (2/12: HKG, ICN) \\
\hline & $\begin{array}{l}\star \text { SBDs used for both domestic and international flights }(1 / 12 \text { : } \\
\text { YYZ) }\end{array}$ \\
\hline & $\star$ SBDs operated without manned counters (1/12: DFW) \\
\hline & $\begin{array}{l}\star \text { Bag Tags can be issued in places other than the air terminal } \\
\text { (e.g., parking entrance) }(1 / 12: \text { FRA) }\end{array}$ \\
\hline & $\begin{array}{l}\star \text { SBD instructions provided in advance through videos }(1 / 12 \text { : } \\
\text { BRU) }\end{array}$ \\
\hline
\end{tabular}

Table 1: SBD security and operational items.

categories: air terrorism, natural accidents, human error, and unknown causes. The analysis results confirmed 1,362 accidents, comprising 169 cases of nature (12\%), 180 cases of air terror (13\%), 309 cases of human error (22\%), and 704 cases of unknown causes (53\%) were detected.

\section{Results}

\section{SBD challenges}

According to the analysis of the previous literature [20] regarding the overseas trends of SBD operation, SBDs are observed to face challenges in terms of security and operation. These are not general, characteristic to all airports, but are rather common aspects observed in several airports examined.

From the security perspective, there are two loopholes in the SBD system that could potentially lead to air terrorism. First, there are no compulsory identification procedures for entering the SBD Zone. This implies that a third person could easily check-in baggage if he/she can obtain the passenger's passport. The second loophole is the absence of SBD security personnel in some airports, which could hamper undertaking security measures during emergencies and detecting strangers attempting to check-in using others' passports. Accordingly, this can make terrorists consider SBD as a tool for air terrorism by consigning bombs/weapons in luggage without the threat of identity exposure.

Regarding SBD operation, four functional problematic cases are 


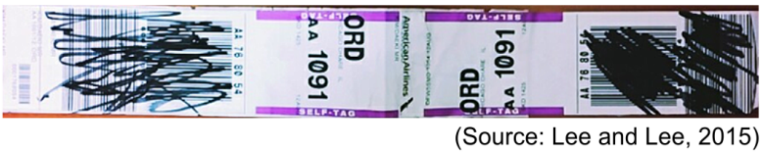

Figure 2: Manually damaged bag tag barcode [2].

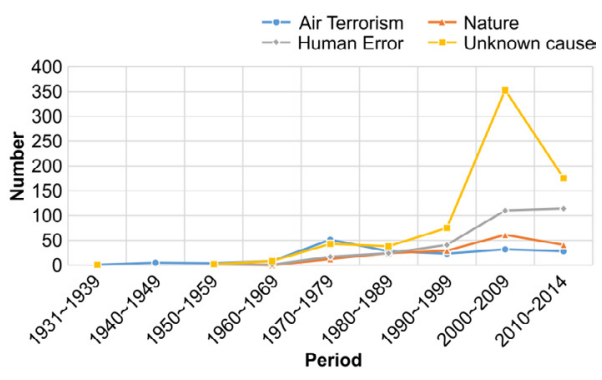

Figure 3: Aviation accident trend.

discovered as follows. First, although one's reservation information is correctly input in the self-kiosk, other passengers' data are displayed in the equipment. Second, group check-ins is not possible through SBD. Third, check-ins for flights booked by code share cannot be processed via SBD. Last, the recognition of bag tags attached to luggage consigned by SBDs fails in airports' baggage handling system (BHS). In the last case, Lee and Lee [19] confirmed that the baggage is sent by destroying the bag tags manually, as seen in Figure 2.

\section{Aviation accidents}

Figure 3 shows the aviation accident trend illustrated by the number of accidents during the examined time span. As shown in Figure 3, all types of accidents are detected from the 1950s. However, this does not mean that there were no accidents before this period; rather, it implies that the accident data were not collected due to the lack of an appropriate accident reporting system. Furthermore, the last period depicted in Figure 3 spans over five years from 2010 to 2014. Therefore, to see the graph in terms of the accident trend during the 10 -year period, the number should be multiplied by two. From this perspective, the graph has a linear shape that increases sharply over time. Accordingly, it can be assumed that all types of accidents will peak between 2010 and 2019.

An interesting characteristic of the accident data is that the causes of more than half of the accidents are unknown. This could be a feature of air transportation, that is, once the airplane takes off, all accidents are isolated and occur in the air [18], which makes accident investigation to identify its causes difficult, despite the existence of technological tools such as the black box and pilot voice recording system. In addition, the reaction of airlines and airports toward accidents could also be a possible reason. To elaborate, systemic accident reporting and investigations tend not to occur for minor accidents. In addition, the airports and airlines involved in an accident tend to address these aspects on their own without adequate reports, to protect their reputations and avoid potential financial losses.

Accidents occur due to abnormal interactions among factors, rather than an individual failure within a system [22]. Since both airplanes and airports are operated by people, the fundamental reason for accidents could be voluntary or involuntary problems created by people. Regardless of whether the level of human errors is severe, these errors could potentially have significant consequences during the occurrence of a series of accidents [22,23]. In fact, human errors are the most frequent cause of aviation accidents [23-25]. The following factors are triggers of human errors: aviation personnel accustomed to organizational conventions, lack of awareness of safety rules, and regulatory loopholes [26-28]. Thus, to control aviation accidents fundamentally, accident prevention policies should be developed with the aim to manage human resources effectively and initiate adequate reporting and investigation of events $[24,21,27]$.

\section{Discussion}

Considering that SBDs and self-service kiosks are located in airports, this study explored the ways to improve airport security by enhancing SBDs' security and efficiency. However, there are some arguments that today's airports are so safe that there is no need to strengthen their security, as compared to stadiums, which have a high concentration of crowds, and are more likely to be attacked and sustain more damage [28]. However, loopholes in airport security could make it easier for terrorist organizations to enter countries, which can cause huge terrorism-related disasters aside from the direct consequences of airport attacks. By analyzing related literature and aviation accidents, this study yields several recommendations to improve SBD security and efficiency as follows.

\section{SBD security}

Implement security regulations for SBDs: According to ICAO Annex 17, aviation safety should be promoted with the aim to protect civil aviation by establishing appropriate policies and regulations that inhibit illegal activities $[29,30]$. Although drafting new security policies is expensive $[31,32]$, accidents caused by the lack of security measures entail much higher costs. Thus, considering this, policies and regulations that reflect reality should be made.

Mandatory deployment of SBD security officers: Since security is the most important aspect in airport access control, security personnel should be deployed in order to prohibit public access to the SBD Zone. However, as airports and airlines place SBD security personnel according to their own plans, in some airports these personnel are absent. Therefore, compulsory regulations should be enacted, which require airports to deploy a certain number of SBD security personnel if they wish to operate SBD services.

Strengthened procedures to identify genuine passengers: Additional identification procedures should be developed in addition to the primary passport check, for instance, input of unique information or biometrics such as fingerprints can be used. Furthermore, when the check-in process starts, an authentication code could be sent to passengers' mobile phones with an aim to notice its initiation. This can be helpful to prevent others from attempting to check-in with the original travelers' information.

Improve information security of SBDs and self-kiosks: Considering the system itself, cyber-attack technology has advanced along with the information technology (IT) [33-36]. As the SBDs link various airlines' boarding information based on certain software, the information security of airports and airlines would be severely threatened if the SBD faces a cyber-attack [37]. Therefore, these systems should implement the ongoing information security checks by establishing a managerial system for data security [36].

Create a security database for active information sharing between organizations: There are several aeronautical institutions at present, and information sharing between them appears relatively 
easy. However, it is actually quite difficult because of the exclusiveness and uncooperativeness of such institutions to take the initiative to share their information on policies and power [38]. In many cases, an organization was unable to prevent a crime due to failure in sharing information, although other organizations held the relevant data [27]. Thus, promoting cooperation among various institutions can be a good way to improve air security by sharing important security information within the governmental organizations [39].

Advertise the use and security of SBDs: Most air travelers generally do not intend to create problems by violating security procedures, aside from abnormal passengers, including terrorists and incidents of air rage. Hence, this current situation may indicate that most security problems occur from passengers' unawareness of the regulations. In fact, aeronautical laws and policies tend to change frequently, which can cause passengers to be confused about the security procedures. Therefore, if security policies are revised or a new technology is introduced, the changes should be advertised as widely as possible [40]. Eventually, this can not only decrease the number of security incidents, but also increase SBD usage rates.

Implement technology to move baggage checked via SBDs to security screening areas: Some airports deploy personnel to move luggage consigned by an SBD to the security zone [9]. This not only increases labor costs, but also causes potential threats to aviation security when problems occur during movement. Therefore, although it requires a high initial investment cost, the rearrangements of the airport or development of a new technology for automatic movement of the baggage should be introduced, as this could reduce operating costs and promote airport security [5].

\section{SBD efficiency}

Operate SBDs for both international and domestic routes: Since SBDs improve the speed of passenger circulation [3,13], airports can increase their passenger capacity by implementing SBDs. Furthermore, if SBDs are operated in relatively uncommon flights, baggage handling can be conducted without additional human resources. Airports can thus increase their long-term competitiveness by reducing operational costs [6].

Unify SBD software: Airports currently use individual self-kiosk systems and provide SBD operation only to certain airlines [9]. If SBDs are operated by a unified system as well as by all airlines, they could promote not only the growth of the self-check-in market but could also increase customer satisfaction. Furthermore, it appears that the simplified SBD program increases the speed of air passenger circulation since passengers on certain airlines can use any machine at the airport aside from those designated for a specific airline.

Improve SBDs and self-kiosks to avoid errors in recognizing reservation information: This can decrease customer reliability on and satisfaction with SBDs. Additionally, reservation confirmation errors can cause additional problems such as duplicated reservations or over booking a specific seat [5]. Thus, airlines should be careful to avoid such errors by enhancing the link between their Departure Control System (DCS) and system speed.

Manned check-in counters should cooperate with SBDs: Customers require some time to adapt to the new technology [6], and this time differs depending on their psychological state and age $[10,11]$. Sudden replacements of existing devices as soon as unmanned technology is invented causes dissatisfaction among customers [11]. Thus, airlines should operate manned counters and SBDs simultaneously for some time so that customers can learn how to use and adapt to the new equipment.

Further develop the 1-step operation method: Unlike the current system, which uses the 2-step method, the 1-step method can complete the entire check-in process with only one device without undergoing other tasks such as additional movement to finish consigning baggage. Therefore, a generalized 1-step method can increase both customer satisfaction and airport spatial efficiency. However, as illustrated above, passengers without any baggage would also have to undergo all procedures, leading to increased check-in time. Thus, based on the condition that there are different modes according to the existence of baggage, it appears that the 1-step method could result in considerably high efficiency.

\section{Limitations}

Since this study uses literature reviews as the main research method, it is possible that not only are there differences from real operations, but also all aviation accidents that occurred between 1931 and 2014 are not included. However, these limitations have less influence on the study results for several reasons. First, many SBD-related studies were published in 2014 and 2015, when SBD was initially introduced, so these publications are good sources to assess the current trends of SBDs. Second, aviation accident cases were collected from reliable Korean government agencies and several books. Therefore, these limitations do not interfere with the objective of the study.

\section{Recommendations for Future Research}

Since implementing new measures requires significant costs and time, risk assessments should be undertaken to enable the public to understand the necessity of new security regulations [32]. However, since risks in airport security comprise "services" and "human error" that are difficult to measure $[25,10]$ security policy makers tend to avoid risk assessment [38-40]. Instead, most security measures tend to stem from reactions to damage from events without valid risk assessments conducted prior to the accidents. In addition, the media, which attribute air terror to the shortage of security [31,32] contribute significantly in creating new security policies.

Unfortunately, these extemporaneous responses have a high potential to create a chain of risks. Thus, airports need systematic countermeasures established via valid risk assessments that are conducted before the events occur. For this, new methods of risk assessment should be created, which can be applied in unmeasurable variables $[41,42]$.

Security is a process of risk assessment that identifies major threats and analyzes a system's vulnerability [43]. Risks can be divided into four categories: identifiable risks by predicting the future environment when a new technology is fully adopted; implied risks by statistical data from accidental events; identified risks by experts' researches; and personally perceived risks by individuals [23]. Considering that SBD was introduced recently, the first concept of risks should be estimated for enhancement of SBD security. In other words, risk assessments should be undertaken by forecasting situations after the SBD is generalized.

No dangers would exist in reality if everything operates relatively smoothly [30]. However, considering that minor errors and problems can lead to an enormous accident, anything could be a risk. Furthermore, risk depends on the viewpoints about certain phenomena [30]. Accordingly, identification of essential risk is based 
Citation: Lee K, Kim H (2018) Improving the Security and Efficiency of Self Bag Drop Systems: Proposals Based on the Current State of the Technology and Aviation Accident Cases. J Astrophys Aerospace Technol 6: 158. doi:10.4172/2329-6542.1000158

on imagination [30]. Since it is especially difficult to measure the airport security risk factors that exist in intangible air services [32], methods for assessing risks to validate new security measures should be selected after identifying potential risks based on forecasts.

Airport security includes physical security and information system security [37]. Thus, establishing airport security requires links between internal and external security. However, since an extremely strong security level decreases the service [40] a balance between them is necessary to achieve both airport safety and customer satisfaction [32]. Security policies are affected by costs for security measures, effectiveness of risk management, and public acceptance [32]. Therefore, to implement the methods to improve SBD security and efficiency identified by this study, cost effectiveness and social acceptability should be satisfied by initiating authentic risk assessments that can measure the level of accidents and dangers caused by problems with SBDs.

\section{Conclusion}

This study examined methods to improve the security and efficiency of SBD systems, which were introduced to address the lack of airport capacity. Additionally, SBDs have advantages in reducing not only passengers' waiting time for check-in, but also airlines' operational cost as SBDs can replace staffed check-in counters. According to the study results, the factors that lead to aviation accidents are absence of relevant regulations and policies, human errors, and inconsistent information sharing among organizations. In order to solve these problems, valid risk assessments should be undertaken. Further, justification for additional security measures should be provided.

\section{Acknowledgement}

This research was funded by Hanseo University.

\section{Conflict of Interest}

The authors have no conflicts of interest to declare.

\section{References}

1. Airbus (2015) Global market forecast during 2015-2034.

2. Lee KS, Ji MS (2014) A study of applicability of self-bag-drop system (unattended baggage handling system) for improvement. Korea Aviation Management Institute Fall Conference Meeting Paper. pp: 347-355.

3. Yang C, Santonino MD (2014) A Kano analysis on the adoption of self-service bag drops at Singapore Changi airport. $18^{\text {th }}$ Air Transport Research Society World Conference, University of Antwerp Stads Campus, Belgium.

4. Yoo KE, Yoo MK (2004) Airport operation and management. Backsan. Paju.

5. Chang HL, Yang $\mathrm{CH}$ (2008) Do airline self-service check-in kiosks meet the needs of passengers. Tour. Manag. 29: 980-993.

6. Choi HSC, Cho J, Kazda P (2010) The effect of culture differences on self check-in kiosk use: An empirical study of Canadian travellers. Int J Tour Sci 10: 117-152.

7. Gkritza K, Niemeier D, Mannering F (2006) Airport security screening and changing passenger satisfaction: An exploratory assessment. J Air Transp Manag 12: 213-219.

8. Hwang KC, Yoo KY (2012) A study on rationalization of aviation security work on the basis of the concept of risk management. J Korean Soc Aeronaut Sci Flight Oper 20: 47-57.

9. Lee SJ, Lee KS, Kim WY (2014a) A study on the application of automation in the domestic check-in through foreign case analysis. Korea Aviation Management Institute Fall Conference Meeting Paper. pp: 513-516.

10. Ueda K, Kurahashi S (2014) How passenger decides a check-in option in an airport. Social Simulation Conference.

11. Wittmer A (2011) Acceptance of self-service check-in at Zurich airport. Res Transp Bus Manag 1: 136-143.
12. Qingji G, Taiwen L, Qijun L (2014) An algorithm for inspecting self checkin airline luggage based on hierarchical clustering and cube-fitting. Sens Transducers 168: 287-293.

13. Kim SS (2016) Airline expansion of unattended ticketing system 'wing'.

14. Kim YM, Yoon SM (2012) u-Airport's domestic and foreign policy trends and best practices. KOTI Aviation Brief 4-7.

15. Lee CU (2015) Present condition of development of IATA fast travel program. KOTI Aviation Brief. 97: 10-11.

16. Ko KN, So DS (2006) Aviation security theory. Backsan. Paju.

17. Price JC, Forrest JS (2014) Practical Aviation Security. (2nd edn). Elsevier Inc. Waltham, Massachusetts, USA.

18. Yoo MK, Kim JS (2014) Aviation security theory. Jinyoungsa, Seoul.

19. Aeronautical Information Portal System (2014) Case of the accidents.

20. Lee KS, Lee SJ (2015) Analysis of foreign cases of self-bag drop system and applicability in Korea for simplification of airport check-in. Korea Aviation Management Institute Fall Conference Meeting Paper. pp: 48-48.

21. Hong SB, Kim WY, Choi YC (2012) The trend analysis about aviation accident and incident in Korea using ECCAIRS data. J Adv Navig Tech 16: 687-696.

22. Cowlagi RV, Saleh JH (2013) Coordinability and consistency in accident causation and prevention: Formal system theoretic concepts for safety in multilevel systems. Risk Anal 33: 420-433.

23. Netjasov F, Janic M (2008) A review of research on risk and safety modelling in civil aviation. J Air Transp Manag 14: 213-220.

24. Han JC, Hwang YC (2013) A study of policy direction for prevention of aviation accident. Korea Transport Institute Nonscheduled Research Report. pp: 1-25.

25. Shappell S, Detwiler C, Holcomb K, Hackworth C, Boquet A, et al. (2007) Human error and commercial aviation accidents: an analysis using the human factors analysis and classification system. Hum Factors: J Hum Factors Ergon Soc 49: 227-242.

26. Lee KS, Seol ES, Young S (2014b) Impact of human factors for student pilots in approved flight training organizations in Korea. Aviation/Aeronautics/Aerospace International Research Conference. Paper 45

27. Yang JH (2012) A study on counter-terrorism facility security in Incheon International Airport: A study on the National police security check in Incheon International Airport (IIA). Hansei University Police Studies.

28. Stewart MG, Mueller J (2014) Cost-benefit analysis of airport security: Are airports too safe? J Air Transp Manag 35: 19-28.

29. Kim CS (2013) Review of ITS integrated airport security system. J Korea Inst Electron Commun Sci 8: 339-344.

30. Salter MB (2008) Imagining numbers: Risk quantification and aviation security Secur Dialogue 39: 243-266.

31. Choi HJ (2010) Risk management plan in accordance with strengthened international logistics security. Korea Bus. Rev 3: 1-26.

32. Shim W, Massacci F, Tedeschi A, Pollini A(2014)A relative cost-benefit approach for evaluating alternative airport security policies. Availability Reliability and Security (ARES) 2014 Ninth International Conference on IEEE. pp: 514-522.

33. Cho HS, Seo DI (2014) Next-generation data protection technology development strategy. J Inst Electron Inf Eng 41: 40-49.

34. Jun HB, Kim JG (2008) A study on research trend and direction of reverse logistics using RFID technology. Entrue J Inf Technol 7: 119-130.

35. Kang YS, Chun YH, Shin YT, Kim JB (2014) A study of the airport model based on security risk Int J Softw Eng Appl 8: 67-74.

36. Park CS, Lee DB, Gwak J (2011) Aviation application field: A study on strengthening corporate and government information security through information security management system. J Korea Navig Inst 15: 1220-1227.

37. Jeong JW (2002) A study on construction of the airport security system using information technology security. Yonsei University Graduate School of Engineering, Seoul, Korea.

38. Speijker LJP, De Jong CJM, Giesberts MKH, Laviv O, Shumer D, et al. (2006) Risk assessment of newly proposed concepts to improve in-flight security. Netherlands Aerospace Centre (NLR). 
Citation: Lee K, Kim H (2018) Improving the Security and Efficiency of Self Bag Drop Systems: Proposals Based on the Current State of the Technology and Aviation Accident Cases. J Astrophys Aerospace Technol 6: 158. doi:10.4172/2329-6542.1000158

Page 6 of 6

39. Kwon JH (2011) Legal status of Germany's response to terrorism and our direction. Korean Association for Local Government Studies Academic Conference Kit pp: 143-161.

40. Udagawa T (2009) Study on airport operation management with the balance between airport security and airport service. Symposium of the Society for Social Management Systems Kochi, Japan.

41. Jeong JH, Yoo KY (2013) A case study on terrorism of international sports events and study on the trend and response to recent terrorism. Korean $\mathrm{J}$ Secur Converg Manag 2: 89-107.

42. Lee DS, Kim JO (2009) Analysis and improvement of airport security check Soc Sci Res 15: 27-62.

43. Horonjeff R, McKelvey F, Sproule W, Young S (2010) Planning and design of airports (5th edn). McGraw-Hill, New York, USA. 